\title{
The Effectiveness of the Promotora (Community Health Worker) Model of Intervention for Improving Pesticide Safety in US/Mexico Border Homes
}

\author{
Susan C. Forster-Cox, Thenral Mangadu, Benjamín Jacquez, Adriana Corona \\ New Mexico State University
}

\begin{abstract}
A variety of environmental health issues occur within homes along the US/Mexico border region. Individuals living in this region are often not aware that specific issues, including pesticide safety, occur in their homes and may not understand the potential adverse effects of pesticide use on their families' health. The Environmental Health/Home Safety Education Project created by the Southern Area Health Education Center at New Mexico State University, utilizes promotoras (community health workers) to educate clients on pesticide safety issues. Data from 367 pre/post tests and home assessments were collected from 2002-2005. The data were analyzed to detect changes in clients' knowledge or behavior as they related to protecting themselves and their families against unsafe pesticide use and storage. Statistically significant changes occurred with both knowledge and behavior in regards to safe pesticide use. Through this culturally appropriate intervention, the promotoras provide practical information allowing clients to make their homes safer.
\end{abstract}

(c) 2007 Californian Journal of Health Promotion. All rights reserved.

Keywords: Home safety, pesticides, US/Mexico Border, New Mexico

\section{Introduction}

The US/Mexico border extends 2000 miles in length from Brownsville, TX to San Diego, CA. It is technically defined as 100 kilometers (62 miles) north and south of this political line (US/Mexico Border Health Commission [USMBHC], 2003). The border region population was 13 million in 2000 based on the Census conducted by Mexico and the US. The population of Mexican Border States grew by $26 \%$ in the decade between 1990 and 2000 . Concurrently, for the same period, the population of the US/Mexico Border States (Texas, New Mexico, Arizona and California) population grew by $20 \%$, which was $50 \%$ higher than the national US growth rate (USMBHC, 2003). It is anticipated that the border region population will reach 19.4 million in the year 2020 (U.S. Environmental Protection Agency [EPA], 2003). The border areas around Cuidad Juarez, Mexico, El Paso, TX and Las Cruces, $\mathrm{NM}$ are in close proximity to the communities served by the Environmental Health/Home Safety Education Project identified in this article. A map of the US/Mexico border region appears below with the $100 \mathrm{~km}$ border area of interest highlighted in a different shade (Figure 1).

Mexico is the only developing nation sharing a border with the United States. The US/Mexico border region has one of the most multi-faceted cultural, economic, and health care structures in the world (Triplett, 2004). It is very common to see immense disparities in access and utilization of health care among people from the same culture, identical ethnic group, same racial background, and even from the same family, when they reside within the US/Mexico border region. The disparities tend to be a combination of a lack of language skills, inadequate education, a poor understanding of values, political agendas, and a non-global commitment to health care (Ruiz-Beltran \& Kamau, 2001). Such disparities also impact the environmental health of the border region. The growing congestion of people and vehicles, uncontrolled urban development, and a lack of basic environmental health and sanitation facilities constitute some very serious environmental threats in many communities on both sides of the US/Mexico border. 


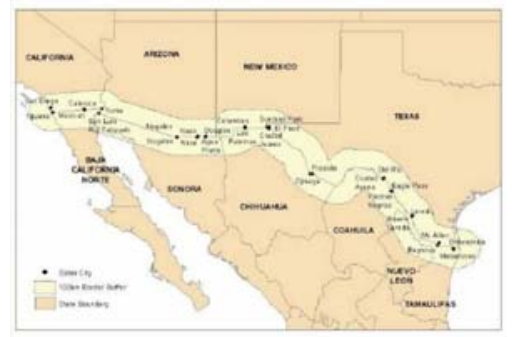

Figure 1

US/Mexico border map with the lighter shaded section indicating the region of interest.

Source: U.S. Mexico Border Health Commission (2005).

\section{Colonias}

Colonias are rural communities located along the US/Mexico border. These communities have a range of unique environmental health issues, which are a result of their population growth that increases diversity and the rate of development. The development of colonias (named after the Spanish word for neighborhood) along the US/Mexico border began in the 1950s. Today, colonias are primarily located on unincorporated lands, which are unchartered and subsequently lack a tax base and police services and often lack some or all of the following basic necessities: running and potable water, sewer and drainage systems, electricity, safe and sanitary housing, and paved roads (U.S. Department of Housing and Urban Development [HUD], 2004). People residing in the colonias also have to deal with issues of illegal dumping, agricultural drainage, and a degradation of the ecosystem (EPA, 2003).

People living in colonias have an average yearly income of $\$ 5,000$, with many employed as seasonal or year round farm workers. The majority of colonia residents are US citizens (85\%) and 97\% are Hispanic (HUD, 2004).

More that 1500 colonias are home to over 500,000 people along the length of the US/Mexico border (University of Texas Pan American, Community Outreach Partnership Center [UTPACOPC], n.d.). Specifically in New Mexico, more than 40,000 individuals reside in 140 different colonias (New Mexico Environment Department [NMED], 2005). Only
$7 \%$ of NM colonias are served by wastewater treatment systems. Large concentrations of these New Mexico colonias lie along the 44-mile stretch of Rio-Grande valley between the El Paso-Juarez metropolitan area and Las Cruces (NMED, 2005).

\section{Issues}

\section{US/Mexico Border Environmental}

A wide array of environmental issues impacts people residing in US/Mexico colonias. The issues, at varying degrees of threat, can include air and water pollution, lead, mercury, and pesticide exposure. This article specifically addresses the issue of pesticide exposure.

Pesticides are used with frequency in homes and agricultural settings along the US/Mexico border. Pesticides have the ability to cause a wide range of acute symptoms to include skin rashes, eye irritation, nausea, diarrhea, sweating, and respiratory difficulties. More severe impacts include a variety of cancers like lymphomas and certain childhood cancers. Pesticides have been linked to reproductive problems in women including miscarriages and birth defects (Quintero-Somaini, et al., 2004). There are also indications that pesticide exposure cause children to suffer from developmental delays (Arcury \& Quandt, 2003).

\section{Home}

Pesticides Usage and Exposure in the

For years, many Latinos have bought and used great amounts of illegally imported pesticides to 
address their mice and roach problems. The United States Environmental Protection Agency (EPA) has tested illegal pesticides and found many of them to be too dangerous for use in homes. The products are sold in the U.S., sometimes in unmarked bags, from street vendors and at local, non-commercial markets known as bodegas or mercados. The products are priced reasonably, yet are often more toxic than legal pesticides sold in the U.S. (QuinteroSomaini, et al., 2004). In addition, some highly toxic products, which are banned in the U.S., are easily accessible in Mexican border cities including Cuidad Juarez (which is close to the area targeted for the environmental health/home safety program) (Roddy, O’Rourke \& Mena, 2004-2005). From the limited research conducted on this topic, it appears that many Latinos take the suggestions of store clerks or advertisements in regards to how much and how often pesticides should be used, as well as safety measures to take when using the products. Most pesticide labels are written in English, which creates barriers to knowledge about safe pesticide use for Latinos whose first language is not English (Quintero-Somaini et al., 2004).

Children are exposed to pesticides in a variety of ways. Exposure can occur at schools, on playgrounds, through pesticide drift, via parents' clothing and dust tracked in from the agricultural fields (take-home exposure), food consumption, exposure to well water, and from the products used in the home to address the family's insect and rodent problems (Faustman, Silbernagel, Fenske, Burbacher, \& Ponce, 2000; QuinteroSomaini et al., 2004). Many of these forms of exposure become part of household dust, which often collects in carpets. The carpet is one place in any home where both pesticides from the outdoors, as well as those applied indoors can collect (Simcox, Fenske, Wolz, Lee, \& Kalman, 1995).

Younger children have a greater risk of pesticide exposure and illness than older children and adults. Based on a child's age, the younger child may have more ways in which he/she can be exposed to pesticides. Infants and toddlers frequently explore their world by using their hands and putting their fingers, toys and other objects in their mouths. Because they move around by crawling, they have frequent contact with floors, carpets, and outside areas where many pesticides are applied, which enhances their exposure to pesticides (Faustman et al., 2000).

Organophosphates (e.g., malathion and diazinon) are the most widely used pesticides and some of the most toxic of agricultural insecticides (Arcury \& Quandt, 2003; Belson et al., 2003). One environmental measurement and correlation study performed in a colonia along the US/Mexico border evaluated young childrens' exposure to environmental levels of organophosphate pesticides (OP) in the household. The young children who participated in this study (7-53 months of age) were found to have high levels of the OP metabolites in their urine and on their hands.

\section{Occupational Exposure to Pesticides Along the US/Mexico Border}

Factors which may contribute to pesticiderelated illnesses in agriculture laborers and their families include low educational levels, recent immigration, low income, low levels of safety education and information, and household crowding; these factors are common among many families living along the US/Mexico border. These factors can create situations in which people have low perceptions of risk from pesticides (Roddy et al., 2004-2005). The consequence of pesticide exposure on the US/Mexico border population is compounded by the undocumented status of many of the agricultural laborers. Many of the undocumented laborers may be reluctant to seek out health care because the cost of health care is prohibitive to those who earn less than the poverty level. Many do not understand that reduced fee scales may be available to them at selected health centers. Some agricultural laborers have fears associated with the healthcare system, poor communication with nurses, and a lack of faith in the medical profession (Poss \& Pierce, 2003).

\section{Project Development}

The Environmental Health/Home Safety Project started as a pilot project in southern Dona Ana County in south central New Mexico in 1999. 
The county shares a border with El Paso, TX and the state of Chihuahua, Mexico. Two New Mexico State University centers, the Southern Area Health Education Center (SoAHEC) and the Border Health Education Training Center (BHETC) were involved in creating the project. The New Mexico Department of Health, Office of Border Health provided funding for the project. The purpose of the pilot project was to conduct in-home assessments using a specially developed home checklist to identify potential environmental health/home safety hazards.
These hazards included unsafe use and storage of pesticides, safe food preparation and storage, fire, electrical and related safety matters. Once the hazards were identified, educational outreach was provided in the home to inform clients of existing safety hazards and how they could remedy some of the situations. The assessments were conducted by specially-trained environmental health promotoras, local informal leaders who lived in the focus communities (Figure 2).

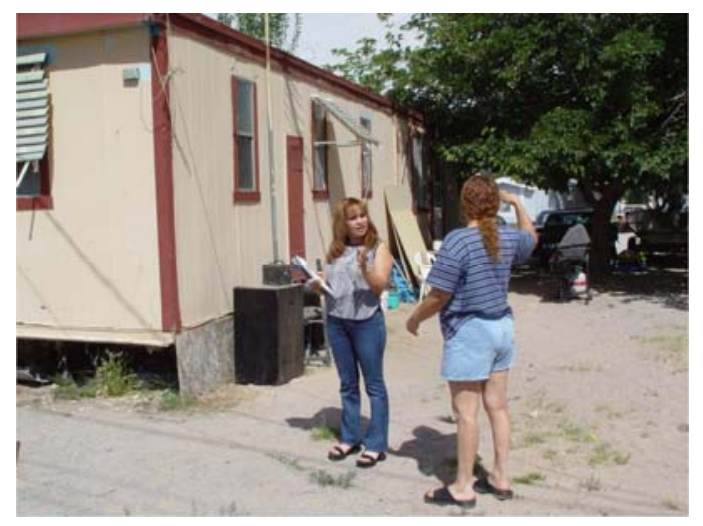

Figure 2

Promotora conducting an environmental health/ home assessment, reviewing conditions outside a home

\section{Theoretical Basis of the Project}

The Environmental Health/Home Safety Project is based on the Health Belief Model, (Janz, Champion, \& Stecher, 2002; U. S. Department of Health and Human Services (USDHHS), 1997). The model is effective in assessing a person's perceived susceptibility, severity, benefits, and barriers, plus cues to action and self-efficacy as they relate to decisions about whether to take action about a health concern.

\section{People 2010 \\ Healthy Border 2010 and Healthy}

The Environmental Health/Home Safety Education Project addresses injury prevention and environmental health. Both of these topics are priority areas as identified in Healthy Border 2010 (U. S. Mexico Border Health Commission
[USMBHC], 2003). Healthy Border 2010 is a bilateral agenda for disease prevention and health promotion in the US/Mexico border region. Similar to Healthy People 2010 (USDHHS, 2000) for the United States, this document is border region specific, providing baseline data for the year 2000 and identified 2010 targets.

\section{Methods}

\section{Study Population}

A total of 367 clients were visited by the promotoras working in the Environmental Health/Home Safety project during the years 2002-2005. Specific demographic data was not collected by the promotoras to avoid resistance to this intervention by prospective clients. Until stronger bonds developed, anxieties harbored by 
some clients included fear of deportation and an initial mistrust of outside or unknown people such as promotoras.

Demographic information observed by the promotoras indicated that most of the clients were economically disadvantaged. The home visits were made during the day and on weekdays, so most of the people who received the intervention were women because they were at home tending to home and child care matters. The vast majority (at least $90 \%$ ) of the targeted clients lived in colonias, which are characterized by scarce educational, economical and healthcare resources.

\section{Intervention}

A set of two environmental health/home safety visits were made by a promotora to every client's residence. The first home visit involved the identification of environmental hazards in and around the homes, educating the client on pesticide safety, and other observed environmental health/home safety issues (Figure 3). The second home visit involved the observation of the client's behavior change towards their ability to reduce the risk of pesticide exposure within the home. All materials and home visits were conducted in Spanish or English, depending upon the client's language preference; the majority of the visits were conducted in Spanish.

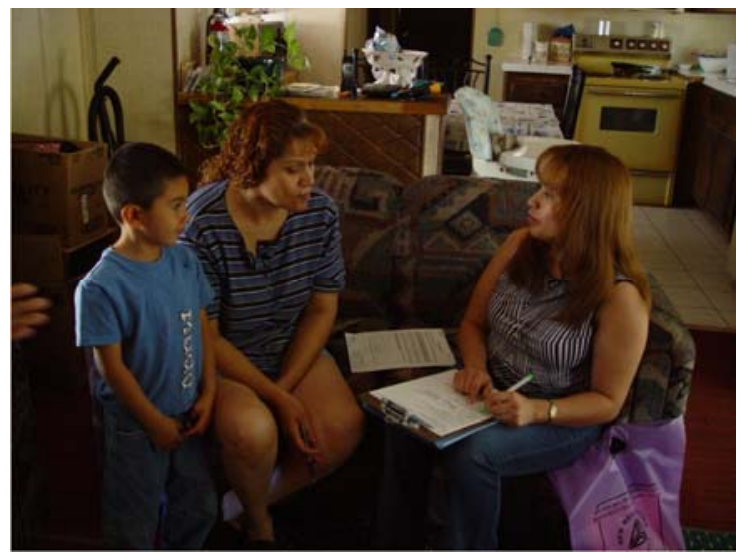

Figure 3

Promotora conducting an environmental health/home assessment, reviewing conditions inside a home.

During the first home visit, which usually lasted for two to three hours, the promotora met with the client and proceeded with the following activities:

- read and explained the consent form and obtained the client's signature if they agreed to the home visit;

- conducted a visual assessment of the home for home-safety hazards;

- reviewed the "Home Assessment Visit, Client Checklist” (see Table 1);
- administered the pre-test to the client; and

- provided education to the client on home safety, including pesticide safety.

The "Home Assessment Visit, Client Checklist" included questions on a wide range of environmental health topics relating to home safety. The checklist could differentiate when the client's answer to a particular question differed from what was actually observed by the promotora. 
Table 1

“Home Assessment Visit, Client Checklist” summary list of major topics/issues evaluated during the visits.

\begin{tabular}{|l|l|}
\hline \multicolumn{1}{|c|}{ Environmental health topics } & \multicolumn{1}{|c|}{ Type of information asked } \\
\hline General home information & $\begin{array}{l}\text { Number of rooms and occupants in the home, if children less than } \\
\text { 12 years of age reside in the home, and if anyone works in the } \\
\text { agricultural fields. }\end{array}$ \\
\hline Asthma and allergies & $\begin{array}{l}\text { Inquire about people who smoke in the home or if clients have } \\
\text { dogs, cats, birds, or carpet. }\end{array}$ \\
\hline Pesticides & $\begin{array}{l}\text { Pesticides used in the home, the different types used, frequency of } \\
\text { use, and manner of handling. }\end{array}$ \\
\hline Lead & Determine if vinyl blinds and/or clay cookware are used. \\
\hline Hazardous household products & $\begin{array}{l}\text { Ask if a range of different hazardous products are within a child's } \\
\text { reach and how products are stored, e.g. bleach in a water bottle. }\end{array}$ \\
\hline Fire and emergencies & $\begin{array}{l}\text { Ask about fire extinguishers, smoke alarms, emergency numbers, } \\
\text { and evacuation plans. }\end{array}$ \\
\hline Electrical safety & $\begin{array}{l}\text { Determine if safety caps are used in outlets, if there are exposed } \\
\text { wires, and methods of home heating. }\end{array}$ \\
\hline Food safety & Ask about refrigerator temperature and chemical storage near food. \\
\hline Outside safety hazards & $\begin{array}{l}\text { Assess presence of sharp tools, pits, animal feces, and/or pesticides } \\
\text { around home. }\end{array}$ \\
\hline Gas safety & $\begin{array}{l}\text { Identify types of cooking stove and heaters and their safety } \\
\text { features. }\end{array}$ \\
\hline
\end{tabular}

At the end of the first visit, a specially designed 8.5” x 11" Home Safety Checklist magnet (in Spanish or English) was placed on the client's refrigerator to serve as a reminder of the specific environmental health/home safety issues that were important for a family's home safety. If a client was to address some specific home or safety hazards before the promotora's second home visit, they were noted on the magnet (see Appendix A). The magnet provided local emergency numbers for the family's information and reference.

A complementary form, "Education Provided," was completed by the promotora after the first visit. The form identified the specific education provided as it related to the completed checklist. For example, if the Home Assessment Visit, Client Checklist indicated that there was an issue with safe pesticides storage in the home, the promotora provided information on proper use and storage (ㅁpendix B) . The promotora noted this information on a form and this became part of the record for the project.

Each client received an incentive package for participating in the project. The package included: a smoke detector, a refrigerator thermometer, electrical safety caps, cabinet safety latches, and educational materials (Appendix C).

The second home visit was made by the Promotora at least two weeks after the initial visit and lasted one to one and a half hours. The promotora conducted a visual observation of the home for any changes the client might have made, based on the recommendations suggested to improve home safety during the first home visit (Figure 4). This information was noted on the original Home Assessment Visit, Client Checklist form. In addition, the promotora administered the post-test to the client during the second home visit. The client was provided with an evaluation form and self-addressed stamped 
envelope, which allowed them the opportunity to provide feedback to the SoAHEC office on the home visit/intervention process. The client received a certificate of completion by mail after the evaluation form was returned to the SoAHEC office.

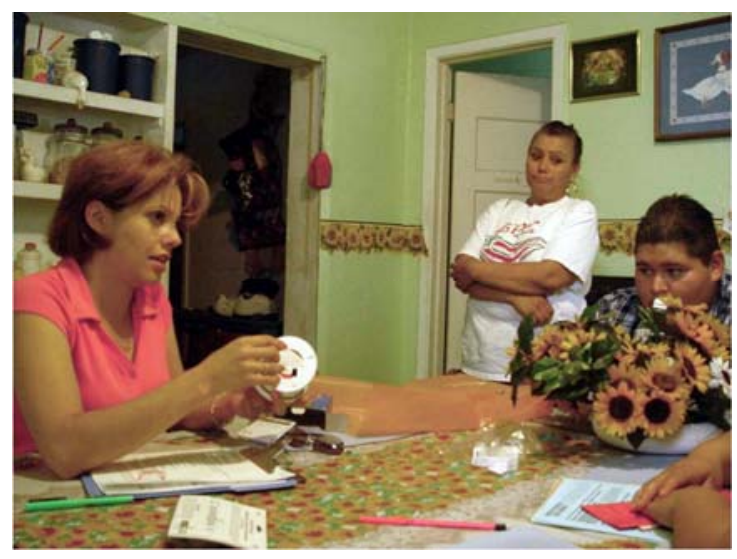

Figure 4

Promotora conducting a follow-up visit in a client's home.

The step-by-step home visit plan for the first and second visits, the forms used, and incentives provided are available in the "The Environmental Health/ Home Safety Tool Kit”. The tool kit is available from the SoAHEC/BHETC web site.

\section{Results}

\section{Statistical Methods}

Data from 367 pre/post tests and home assessments conducted from 2002-2005, were analyzed to detect any change in knowledge or initial behavior following the intervention that was related to clients protecting themselves and their families against pesticide exposure. The Fishers Exact Test and binomial test were used to determine if any statistically significant change in knowledge or initial behavior related to pesticide safety was observed among the participating clients. Variables analyzed include knowledge of utilization of protective clothing while using pesticides, knowledge of proper storage of pesticides, behavior change towards wearing protective clothing while using pesticides, and behavior change in enforcing childproofing pesticides stored in and around the home. Data for the variables measuring change in knowledge were obtained from pre/post tests and the data for the variables estimating change in behavior was obtained from the first and second home assessments performed by the promotoras.

\section{Data Analysis Results}

A statistically significant increase in perceived knowledge of methods to protect against pesticide exposure, $\mathrm{p}<0.001$, was observed when data from three years (2002-2005) of the Environmental Health/Home Safety Project was analyzed, as indicated in Table 2 below. Eighteen participants, who answered incorrectly in the pre-test about wearing protective clothing while using pesticides, indicated in the post-test that it is ideal to use protective clothing to avoid being exposed to pesticides. In addition, all but one of the clients who did not know about safe storage of pesticides in their homes (25 out of 26) during the first home visit, indicated in the post-test that pesticides should not be within the reach of children, $\mathrm{p}=0.002$. 
Table 2

Change in knowledge/awareness related to pesticide safety among the clients served as evidenced in the post-test scores for Years 2002-2005 combined $(n=367)$.

\begin{tabular}{|c|c|c|c|c|}
\hline \multirow[b]{2}{*}{ Question } & & \multicolumn{2}{|c|}{ Posttest } & \multirow[b]{2}{*}{ p-value ${ }^{1}$} \\
\hline & & Incorrect & Correct & \\
\hline $\begin{array}{l}\text { How can you protect yourself against } \\
\text { pesticides? }\end{array}$ & $\begin{array}{l}\text { Pretest } \\
\text { Incorrect } \\
\text { Correct }\end{array}$ & $\begin{array}{l}0(0.0 \%) \\
2(0.5 \%)\end{array}$ & $\begin{array}{c}18(4.9 \%) \\
347(94.6 \%)\end{array}$ & $<0.001$ \\
\hline $\begin{array}{l}\text { Which of the following should you not } \\
\text { have within the reach of children? }\end{array}$ & $\begin{array}{l}\text { Pretest } \\
\text { Incorrect } \\
\text { Correct }\end{array}$ & $\begin{array}{l}1(0.3 \%) \\
7(1.9 \%)\end{array}$ & $\begin{array}{c}25 \text { (6.9\%) } \\
330 \text { (90.9\%) }\end{array}$ & 0.002 \\
\hline
\end{tabular}

${ }^{1}$ Binomial test

Overall, statistically significant changes in initial behavior towards protecting themselves against pesticide exposure were observed in $61.9 \%$ of the clients served by the Environmental Health/Home Safety Project from 2002- 2005 (n $=367$ ). Almost $62 \%$ of the clients served from 2002-2005 exhibited initial behavior change by using protective clothing during pesticide application around the house by the time of the second home assessment, $\mathrm{p}<0.001$, see Table 3 below. Statistically significant behavior change in storage of pesticides was observed in 193 individuals reached through this project. Fiftyseven percent $(n=193)$ of the clients who were observed during the first home assessment to store pesticides in places accessible to children in the home had child-proofed stored pesticides by the second home assessment, $\mathrm{p}<0.001$.

Table 3

Percentage of clients who exhibited behavior change pertaining to reduction of risk to pesticide exposure by the second home assessment during the years 2002-2005 (n=367).

\begin{tabular}{|c|c|c|c|c|}
\hline \multirow[b]{2}{*}{ Question } & & \multicolumn{2}{|c|}{ Second visit behavior } & \multirow[b]{2}{*}{ p value } \\
\hline & & No & Yes & \\
\hline $\begin{array}{l}\text { Do you use gloves or face masks for } \\
\text { protection when applying pesticides? } \\
\text { (calculated in clients who use pesticides) }\end{array}$ & $\begin{array}{l}\text { First visit behavior } \\
\text { No } \\
\text { Yes }\end{array}$ & $\begin{array}{l}4(2.2 \%) \\
1(0.6 \%)\end{array}$ & $\begin{array}{l}112(61.9 \%) \\
64(35.4 \%)\end{array}$ & $<0.001$ \\
\hline $\begin{array}{l}\text { Can children reach pesticides stored in the } \\
\text { home? }\end{array}$ & $\begin{array}{l}\text { First visit behavior } \\
\text { No } \\
\text { Yes }\end{array}$ & $\begin{array}{c}31(9.2 \%) \\
193(57.1 \%)\end{array}$ & $\begin{array}{c}13(3.8 \%) \\
101(29.9 \%)\end{array}$ & $<0.001$ \\
\hline
\end{tabular}

${ }^{1}$ Binomial test

\section{Discussion}

The data presented above indicates that the education and support provided by the promotoras had a positive effect on clients in regards to their safe use and storage of pesticides in the home. Clients increased their knowledge about safe use and storage of pesticides in their first home visit with the promotora.
Consequently, the clients demonstrated behavior changes at the time of the second home visit by indicating how and where they were safely storing their pesticides. Overall, the project demonstrates the effectiveness of the promotora model of intervention for improving pesticide safety in many homes, which are located along the US/Mexico border. A follow-up assessment 
of behavior change among the 367 clients within the next few years would be ideal to account for the impact of the Environmental Health/Home Safety Project.

The promotoras involved in this project continually demonstrated that they were successful in gaining the trust and confidence of the clients, who allowed them into their homes. The practice of someone entering a person's home and assessing it for health and safety matters can be perceived as intimidating and potentially embarrassing. The practice of an outsider observing a person's household product storage methods is often deemed to be unacceptably invasive or intrusive (Roddy et al., 2004-2005), yet the matter was successfully overcome by the promotoras in this project. The promotoras' ability to gain the trust and support of the clients is a significant reason behind the success of this program. They have the ability to inform and educate in a manner that clients perceived as supportive; this is a key issue when conducting a program of this nature.

Part of the challenge in gaining the trust of community members lies in the fact that many of these individuals and families are not comfortable with programs that collect information on their living conditions. They are uncomfortable with the idea that information on their homes may not be kept confidential, and in some cases, could be shared with government entities. The promotoras in this program have worked hard to gain peoples trust, in large part due to the fact that they are members of the same communities being served and understand the concerns. By talking with the community members and valuing their concerns, the promotoras gain peoples trust and clients are thereby willing to allow the program to come to their homes. Many times the clients made referrals to other community members in which they recommended the promotoras to visit their homes, reflecting the level of trust which was established.

The authors acknowledge the limitations of this study as: not being of a random controlled design and the inability to focus on individual occupational risk factors and exposure levels of the clients to pesticides. It must be pointed out that these limitations were mainly because this project is primarily an intervention based on the Promotora model and that there were funding constraints existed for research activities.

\section{Conclusion}

The development and implementation of a culturally sensitive and practical Environmental Health/Home Safety Education Project along the US/Mexico border has shown to be effective in regards to pesticide safety. Utilizing promotoras to educate clients about environmental home safety issues positively influences the change in knowledge and behavior among the majority of the clients visited. During the period of 20022005 , over 360 clients allowed promotoras to enter their homes and conduct an environmental safety checklist, which included pesticide safety. Upon learning the results of the checklist, clients were provided practical information on how they could improve the safety of their homes. Based on the Health Belief Model, the clients learned that they had a potentially dangerous situation in their homes, they perceived the risk, gained information as to how they could make their homes safer (lessen the risk), and ultimately took the necessary steps of incorporating safety recommendations, and making their homes safer for their families. The promotoras provided the clients with practical bilingual information in a safe, trustworthy manner about how they could make their home environments safer. Home safety can be achieved in border communities using a culturally sensitive, community health worker/Promotora model that encourages clients to create safe home environments and safer pesticide use.

\section{References}

Arcury, T. A., \& Quandt, S. A. (2003). Pesticides at work and at home: Exposure of migrant farmworkers. Lancet, 362, 2021. 
Belson, M., Kieszak, S., Watson, W., Blindauer, K. M., Phan, K., Backer, L., \& Rubin, C. (2003). Childhood pesticide exposures on the Texas-Mexico Border: Clinical manifestations and poison center use. American Journal of Public Health, 93, 1310-1315.

Faustman, E. M., Silbernagel, S. M., Fenske, R. A., Burbacher, T. M., \& Ponce, R. A. (2000). Mechanisms underlying children's susceptibility to environmental toxicants. Environmental Health Perspective, 108 (suppl 1), 13-21.

Janz, N. K., Champion, V. L. \& Stecher, V. J. (2002). The health belief model. In K. Glanz, B. K. Rimer, \& F. M. Lewis (Eds.), Health behavior and health education theory, research and practice. (3rd ed.). San Francisco, CA: Jossey Bass.

Poss, J. E., \& Pierce, R. (2003). Characteristics of selected migrant farmworkers in West Texas and Southern New Mexico. Californian Journal of Health Promotion, 1(2), 138-147.

Quintero-Somaini, A., Quirindongo, M., Arévalo, E., Lashof, D., Olson, E., \& Solomon, G. (2004). Hidden danger: Environmental health threats in the latino community. New York, NY: Natural Resources Defense Council.

Roddy, M. E., O’Rourke, K. M., \& Mena, K. (2004-2005). Factors associated with increased risk for acute unintentional childhood poisoning among children living on the U.S.-Mexico border. International Quarterly of Community Health Education, 23(4), 295-309.

Ruiz-Beltran, M., \& Kamau, J. K. (2001). The socio-economic and cultural impediments to well-being along the US-Mexico Border. Journal of Community Health, 26(2), 123-132.

Salameh, P. R., Baldi, I., Brochard, P., Raherison, C., Abi Saleh, B., \& Salamon, R. (2003). Respiratory symptoms in children and exposures to pesticides. European Respiratory Journal, 22, 507-12.

Simcox, N. J., Fenske, R. A., Wolz, S. A., Lee, I. C., \& Kalman, D. A. (1995). Pesticides in household dust and soil: Exposure pathways for children of agricultural families. Environmental Health Perspective, 103, 1126-1134.

Triplett, W. (2004). Migrant farmworkers. The CQ Researcher, 14, 829-852.

U. S. Department of Health and Human Services. (2000). Healthy People 2010: Understanding and improving health (2nd ed). Washington, DC: U. S. Government Printing Office.

U. S. Department of Health and Human Services. (1997). Theory at a glance: A guide to health promotion practice (NCI Publication No. 97-3896). Bethesda, MD: Author

U. S. Department of Housing and Urban Development. (2004). Facts about farmworkers and colonias. Retrieved October 5, 2005, from http://www.hud.gov/groups/farmwkercolonia.cfm

U. S. Environmental Protection Agency. (2003). Border 2012: U.S.-México environmental program. Washington, DC: U. S. Government Printing Office.

U. S. Mexico Border Health Commission. (2005). United States -Mexico Border Health Commission (BHC) 2005 report. El Paso, TX.: Author. Retrieved December 29, 2006, from http://www.borderhealth.org/files/res_589.pdf

U. S. Mexico Border Health Commission. (2003). Healthy Border 2010: An agenda for improving health on the United States-Mexico border. El Paso, TX.: Author.

University of Texas Pan American, Community Outreach Partnership Center. (n.d.). National colonia clearinghouse. Retrieved October 20, 2005, from http://coserve1.panam.edu/copc/colonias.html

\section{Acknowledgements}

This project evolved due to the efforts of many people including the New Mexico Department of Health, Office of Border Health which provided the core funding for this project. The original promotoras, Claudia Levya, Hermelinda Garcia, Lucy Palomino, and Maria Celia Sigala, were key in making it the success it has been. Betty Skipper, Ph.D., Professor, University of New Mexico, Family and Community Medicine, provided excellent statistical expertise and guidance. 
$\underline{\text { Author Information }}$

Susan C. Forster-Cox, Ph.D., M.P.H., C.H.E.S*

Assistant Professor

New Mexico State University

Department of Health Sciences

PO Box 30001, MSC 3HLS

Las Cruces, NM 88003

Ph.: 505-646-2183

E-Mail: sforster@nmsu.edu

Thenral Mangadu, M.D., M.P.H.

Evaluator

Southern Area Health Education Center (SoAHEC)

New Mexico State University

PO Box 30001, MSC AHC

Las Cruces, NM 88003

Ph.: 505-646-3441

E-Mail: tmangadu@nmsu.edu

Benjamín Jacquez, M.S.

Director

Southern Area Health Education Center (SoAHEC)

New Mexico State University

PO Box 30001, MSC AHC

Las Cruces, NM 88003

Ph.: 505-646-3441

E-Mail: jacquez@nmsu.edu

Adriana Corona, M.B.A.

Program Coordinator

Southern Area Health Education Center (SoAHEC)

New Mexico State University

PO Box 30001, MSC AHC

Las Cruces, NM 88003

Ph.: 505-646-3441

E-Mail: acorona@nmsu.edu

* corresponding author 


\section{Appendix A}

Refrigerator magnet (English version) provided to a client at the end of first visit

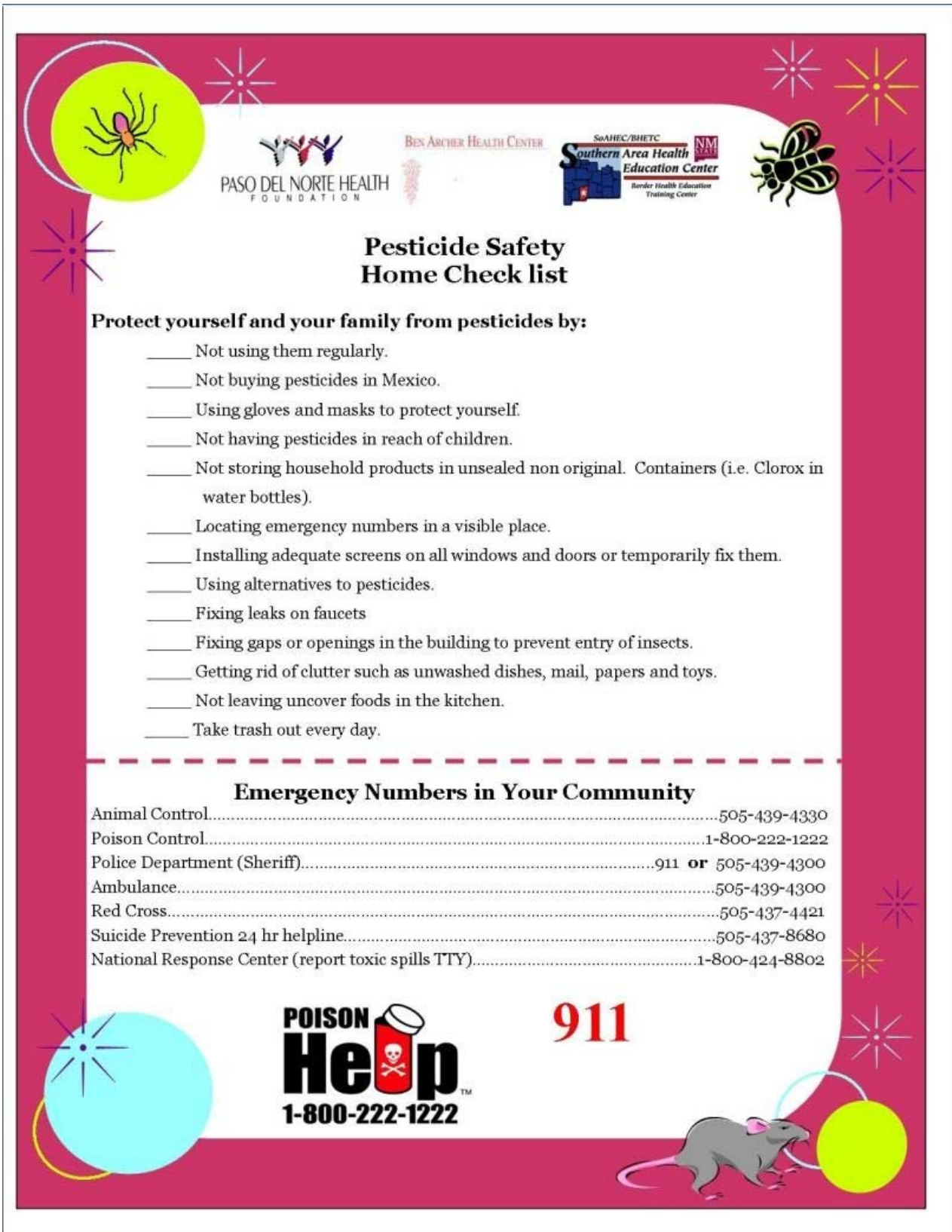




\section{Appendix B}

Examples of educational materials provided to clients

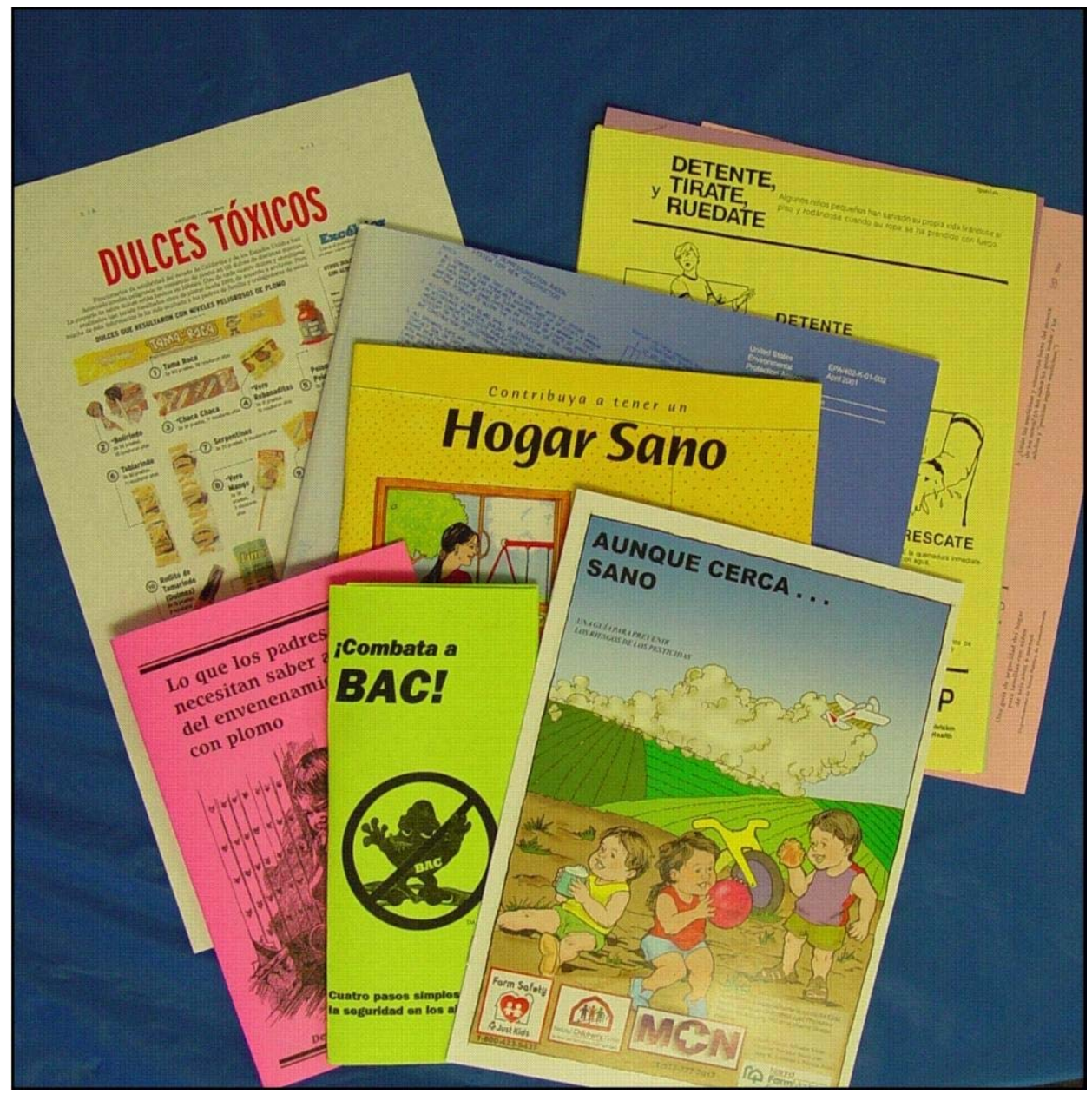




\section{Appendix C}

Incentive package provided to clients.

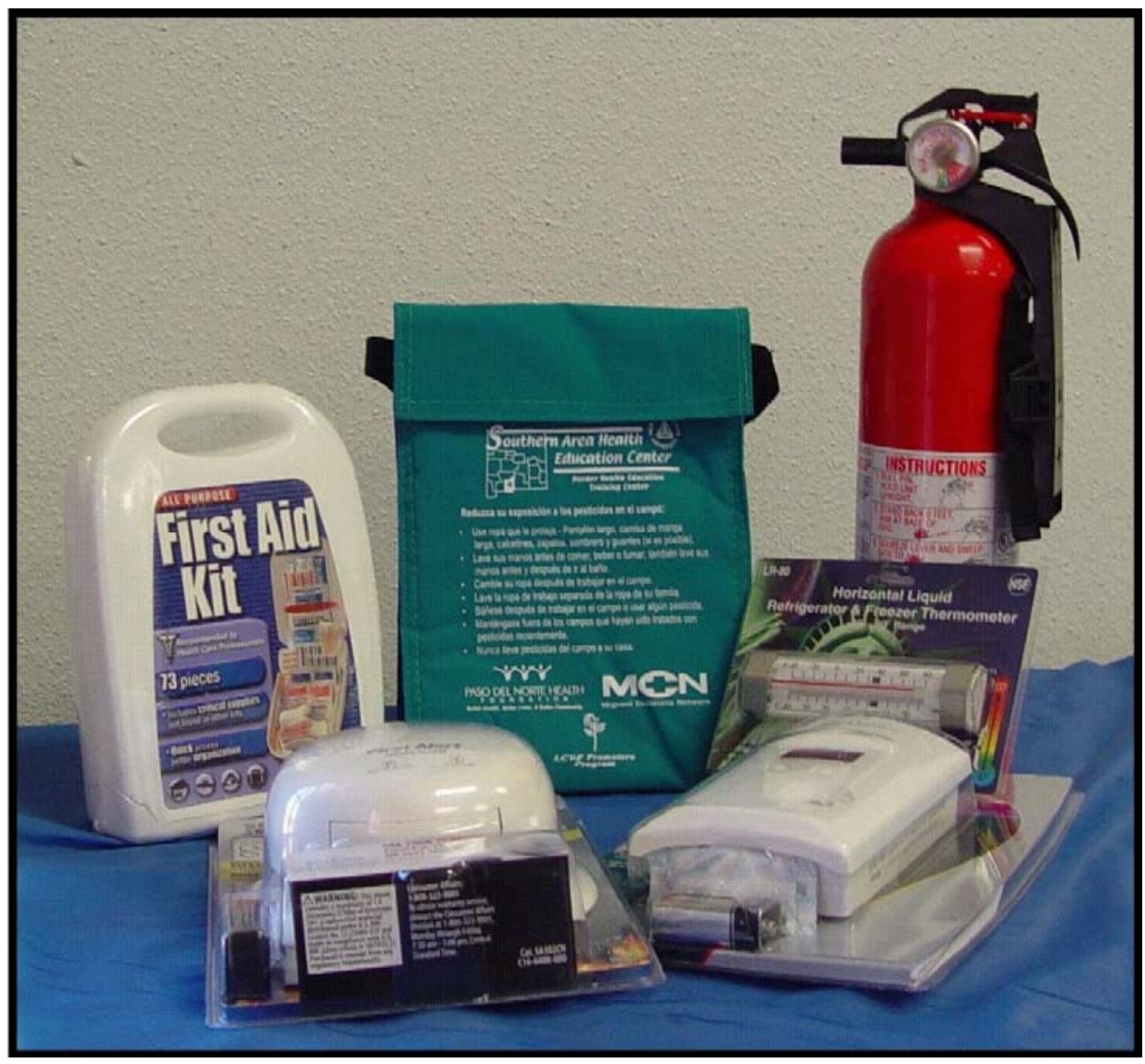

